\title{
Publisher's Note: Using gate-modulated Raman scattering and electron-phonon interactions to probe single-layer graphene: A different approach to assign phonon combination modes
}

[Phys. Rev. B 86, 195434 (2012)]

\author{
D. L. Mafra, J. Kong, K. Sato, R. Saito, M. S. Dresselhaus, and P. T. Araujo
}

(Received 4 December 2012; published 7 December 2012)

DOI: 10.1103/PhysRevB.86.239902

PACS number(s): 73.20.Hb, 73.22.-f, 78.30.Na, 78.67.Ch, 99.10.Fg

This paper was published online on 30 November 2012 with an omission of an author byline footnote. P. T. Araujo's byline footnote should read as "*Corresponding author: ptaraujo@mit.edu". The byline footnote has been added as of 4 December 2012. The byline footnote is present in the printed version of the journal. 